\title{
LA ELIMINACIÓN DE LOS REFERENTES REPUBLICANOS TRAS LA GUERRA CIVIL: EL PROCESO CONTRA LUIS ARRÁEZ MARTÍNEZ, GOBERNADOR CIVIL DE MÁLAGA
}

THE ELIMINATION OF REPUBLICANS REFERENCES IN THE POST-CIVIL WAR FRANCOIST REPRESSION IN SPAIN: THE MILITARY TRIAL AGAINST LUIS ARRÁEZ MARTIINEZ, CIVIL GOVERNOR OF MÁLAGA

\author{
Pedro Payá López \\ Universidad de Alicante
}

Entregado el 11-11-2014 y aceptado el 19-6-2015

\begin{abstract}
Resumen: Este artículo estudia las formas de persecución y aniquilación del enemigo político durante la posguerra española mediante el análisis del proceso seguido contra un alto cargo de la Segunda República: el gobernador civil de Málaga, Luis Arráez Martínez. Más concretamente, partiendo de la hipótesis de que no es posible comprender aspectos centrales de la represión judicial franquista sin examinar de cerca las condiciones sociales en las que se hizo efectiva, indaga en la responsabilidad que los agentes locales que colaboraron con las autoridades militares que incoaron el procedimiento tuvieron en el resultado final del mismo. El Estado era el organizador de la represión, instrumento con el que conseguir unos objetivos muy definidos y que ya estaban en la base de la rebelión de 1936 como era la «limpieza política», pero es el conocimiento de la realidad local lo que permite comprobar que fueron autoridades locales y vecinos quienes se erigieron en pieza principal para conseguir el éxito de la misma.
\end{abstract}

Palabras clave: Guerra Civil Española, represión franquista, consejos de guerra, autoridades locales, vecinos, enemigo, Luis Arráez Martínez. 


\begin{abstract}
This contribution studies the forms of political persecution and annihilation of the enemies after the Spanish Civil War through the analysis of the military trial against a senior official in the Republican Civil administration: the civil Governor Luis Arráez Martínez. More precisely, the article focuses on the study of the social conditions which made possible judicial repression during the Franco Regime and, from this point of view, it explores the contribution of the local authorities to the process of Luis Arráez. In fact, the State was the organizer of the repression with which Franco tried to achieve precise targets as, for example, the political cleansing. All these objectives were at the basis of Franco's uprising in 1936. The author shows that the political repression was based on the local authorities and the neighbors of the victims. All of them played a major role in the development and the success of francoist repressive strategies.
\end{abstract}

Key words: Spanish Civil War, francoist repression, military trials, local authorities, neighbors, enemy, Luis Arráez Martínez. 
Mucho se ha avanzado en el conocimiento de la represión franquista desde que a principios de los años ochenta comenzaran a publicarse los primeros estudios teóricos que ponían en cuestión y demostraban la falta de validez de las cifras recogidas por Salas Larrazábal. ${ }^{1}$ Ello se vio reforzado por la aparición de las continuas y necesarias monografías que, desde la base del conocimiento empírico, se ocuparon de contabilizar sistemáticamente el número de víctimas en las provincias que estudiaban desde postulados metodológicos que, sin embargo, no descuidaban las aportaciones teóricas al conocimiento de la represión y la violencia política, y que posibilitaron la publicación de un primer estado de la cuestión en el libro coordinado por Santos Juliá Víctimas de la guerra civil. ${ }^{2}$ Posteriormente, las investigaciones sobre la represión franquista fueron diversificando su objeto de estudio, y del cómputo de víctimas se fue ampliando hacia un mejor conocimiento de las formas de represión cotidiana, ${ }^{3}$ del universo penitenciario y los campos de concentración, ${ }^{4}$ y de los discursos justificativos de la violencia contra el enemigo. ${ }^{5}$ Estos avances, y su confluencia teórica con la historiografía internacional, han permitido la aparición de visiones de conjunto que comienzan a dibujar diferentes marcos interpretativos, que tienen en común el hecho de enmarcar la multifacética represión dentro del amplio campo de la violencia política y las representaciones de una cultura de guerra y de «la victoria» sobre las que se trataba de legitimar. ${ }^{6}$ Una re-

${ }^{1}$ Alberto Reig Tapia, Ideología e historia. Sobre la represión franquista y la guerra civil, Akal, Madrid, 1984.

2 Santos Juliá, Víctimas de la guerra civil, Temas de Hoy, Madrid, 1999.

${ }^{3}$ Conxita Mir, Vivir es sobrevivir. Justicia, orden y marginación en la Cataluña rural de posguerra, Milenio, Lleida, 2000.

${ }^{4}$ Ricard Vinyes, Irredentas. Las presas políticas y sus hijos en las cárceles franquistas, Temas de Hoy, Madrid, 2002; Carme Molinero, Margarida Sala y Jaume Sobrequés (eds.), Una inmensa prisión. Los campos de concentración y las prisiones durante la guerra civil y el franquismo, Crítica, Barcelona, 2003; Javier Rodrigo, Cautivos. Los campos de concentración franquistas, Crítica, Barcelona, 2005.

${ }^{5}$ Francisco Sevillano Calero, Rojos. La representación del enemigo en la guerra civil, Alianza, Madrid, 2007.

${ }_{6}$ Javier Rodrigo, Hasta la raíz. Violencia durante la guerra civil y la dictadura franquista, Alianza, Madrid, 2008; Julio Prada Rodríguez, La España masacrada. La represión franquista de guerra y posguerra, Alianza, Madrid, 2010; Francisco Espinosa Maestre (ed.), Violencia roja y azul. España, 1936-1950, Crítica, Barcelona, 2010; Gutmaro Gómez Bravo y Jorge Marco, La obra del miedo. Violencia y sociedad en la España franquista (1936-1951), Península, Madrid, 2011; Santiago Vega Sombría, La política del miedo. El papel de la represión en el franquismo, Crítica, Barcelona, 2011; Paul Preston, El holocausto español, Debate, Madrid, 2011. 
presión que ya es considerada como el elemento definitorio del régimen nacido de la guerra civil, base sobre la que se apoyó su sistema. ${ }^{7}$

Sin embargo, y como lo ha expresado Saul Friedländer, para que la historia de una colectividad no acabe convirtiéndose en estadística, es necesario que sea contada también a través de la narración de las vidas individuales de aquellos que sufrieron aquel destino ${ }^{8}$ y destacar así la unicidad de cada una de aquellas víctimas que fueron homogeneizadas por los discursos de sus verdugos, cuando fueron categorizadas como un todo: los rojos. A su vez, un enfoque de esta naturaleza permite trascender lo individual para afrontar problemas de fondo, históricos y morales, como los que tienen que ver con la naturaleza de la violencia y la responsabilidad de los distintos actores, ${ }^{9}$ poniendo sobre la mesa la actuación de individuos concretos cuya responsabilidad personal impide que sean reducidos a entidades abstractas. ${ }^{10}$ Importantes aportaciones han dado ya los estudios sobre el nazismo y el fascismo durante la ocupación alemana. ${ }^{11}$ En España, sin embargo, salvo contadas y notables excepciones, seguimos careciendo de estudios significativos que se pregunten, desde el estudio local de la violencia, por la responsabilidad de los sujetos que la ejercieron o alentaron y permitieron que se desarrollara. ${ }^{12}$

7 Julio Aróstegui (coord.), Franco: La represión como sistema, Flor del Viento, Barcelona, 2012.

${ }^{8}$ Saul Friedländer, El Tercer Reich y los judios (1933-1939). Los años de la persecución, Galaxia Gutenberg/Círculo de Lectores, Barcelona, 2009, p. 21. Como ha escrito Annette Wieviorka, no se trata de trasmitir una desgracia individual, sino de un sufrimiento nacido de un acontecimiento histórico que se fragmenta en una serie de historias individuales. Annette Wieviorka, L'Ère du témoin, Hachette, Paris, 2002, pp. 178-179.

${ }^{9}$ Claudio Pavone, Una guerra civile. Saggio storico sulla moralità nella Resistenza, Bollati Boringhieri, Torino, 1991, p. 414.

10 Tzvetan Todorov, Été 1944: scénes de guerre civil, Seuil, Paris, 1994, p. XVII.

11 Robert Gellately, The Gestapo and German Society: Enforcing Racial Policy, 19331945, Oxford University Press, 1990; Eric A. Johnson, Nazi Terror. The Gestapo, Jews, and ordinary Germans. Basic Books, New York, 2000; Michele Battini y Paolo Pezzino, Guerra ai civil. Occupacione tedesca e política del masacro. Toscana, 1944, Marsilio, Venezia, 1997; Gabriella Gribaudi, «Guerra, Violenza, Responsabilità. Alcuni volumi sui massacre nazisti in Italia», Quaderni Storici, 100, 1999, pp. 135-150.

12 Peter Anderson, The Francoist Military Trials. Terror and Complicity, 1939-1945, Routledge, New York, 2010; Francisco Cobo Romero y María Teresa Ortega López, Franquismo y posguerra en Andalucía Oriental. Represión, castigo a los vencidos y apoyos sociales al régimen franquista, 1936-1950, Universidad de Granada, 2005; Francisco Espinosa Maestre, La justicia de Queipo. Violencia selectiva y terror fascista en la II División en 1936: Sevilla, Huelva, Cádiz, Córdoba, Málaga y Badajoz, Crítica, Barcelona, 2006; Carlos 
Tratando de profundizar en esta línea, este artículo estudia las formas de persecución y aniquilación del enemigo político durante la posguerra española mediante el análisis del proceso seguido contra un alto cargo de la Segunda República: el gobernador civil de Málaga, Luis Arráez Martínez. Más concretamente, partiendo de la hipótesis de que no es posible comprender aspectos centrales de la represión judicial franquista sin examinar de cerca las condiciones sociales en las que se hizo efectiva, indaga en la responsabilidad que los agentes locales que colaboraron con las autoridades militares que incoaron el procedimiento tuvieron en el resultado final del mismo. La reducción de escala nos ha permitido examinar las conexiones existentes entre los verdugos y la víctima en relación a las características sociales y las vivencias políticas de la comunidad local de referencia: cuáles eran sus prejuicios, sus intereses no declarados, cuáles sus posibles encuentros y desencuentros en el pasado más reciente, y el peso del recuerdo de los mismos. El Estado era el organizador de la represión, instrumento con el que conseguir unos objetivos muy definidos y que ya estaban en la base de la rebelión de 1936 como era la «limpieza política», pero es el conocimiento de la realidad local lo que permite comprobar que fueron autoridades locales y vecinos quienes se erigieron en pieza principal para conseguir el éxito de la misma.

\section{Notas sobre la trayectoria social y política de Luis Arráez Martínez}

En su turno de palabra, el abogado expuso su defensa de Luis Arráez ante lo genérico de las acusaciones que sobre él pesaban:

...¿¿hay algún cargo concreto contra Luis Arráez que le defina terminantemente como autor o inductor de delito? Imposible, tenemos la certeza de que no pasará de delitos indiciarios cuanto motive su situación; no dudamos que hayan podido forjarse estos, sobre cualquier malquerencia por ideas, competencia industrial o animosidad, frecuentes en localidades pequeñas donde la pasión encarna fácilmente entre convecinos, pero cargo concreto, prueba indestructible, estamos seguros de que no habrá

Gil Andrés, Lejos del Frente. La guerra civil en la Rioja Alta, Crítica, Barcelona, 2006; Glicerio Sánchez Recio, Operación quirúrgica en el cuerpo social. La represión política en Monóvar (1936-1943), Publicaciones de la Universidad de Alicante, 2014; Javier Gómez Calvo, Matar, purgar, sanar. La represión franquista en Álava, Técnos, Madrid, 2014. Para el periodo inmediatamente anterior, Fernando del Rey, Paisanos en lucha. Exclusión política y violencia en la Segunda República española, Biblioteca Nueva, Madrid, 2008. 
ninguno. Y en el supuesto hipotético de que hubiera imputación concreta ies de tal naturaleza el cargo que imponga necesariamente pena superior a prisión correccional? Imposible de toda imposibilidad. Si del sumario resultara tal cosa, tenemos la certeza de que los testigos que hayan señalado concretamente a Arráez habrán imputado falsa e inconscientemente y sin noción de la injusticia y el daño que iban a causar.

Evidentemente, ninguna de estas palabras fue dicha por el abogado de Luis Arráez ante el Consejo de Guerra que lo condenó a muerte el 16 de abril de 1940. Tampoco estamos ante una reconstrucción ficticia de la exposición que pudiera haber realizado, sino años antes, el 17 de diciembre de 1934, en el momento en el que el abogado Julio Ibáñez Pérez-Monte exponía la defensa de Luis Arráez contra las imputaciones derivadas de su posible implicación en los acontecimientos revolucionarios de octubre de 1934 en la localidad de Petrer. En esa ocasión, Luis Arráez pudo defenderse y, al final, el sumario acabaría siendo sobreseído cuando se supo que había un testimonio, dado antes incluso de su detención, que lo exculpaba rotundamente, pero que el sargento de la guardia civil, Arcadio Sánchez, no incluyó en sus diligencias. ${ }^{13}$

Nacido en el seno de una familia de trabajadores el 21 de abril de 1895 en Almansa (Albacete), en su juventud emigró junto al resto de la misma a la localidad alicantina de Elda, atraídos por las posibilidades que ofrecía una ciudad que estaba creciendo sostenidamente al amparo del desarrollo de la industria del calzado, además de presentar un destacado dinamismo cultural. De formación autodidacta, emprendedor, y con unas arraigadas ideas socialistas, pronto entró en contacto con la burguesía de base republicana, ingresando en la logia masónica Amor, ${ }^{14}$ a la vez que comenzaba su prolija actividad política dentro de la agrupación socialista local, a la que representó en los congresos extraordinarios de 1927, 1928 y 1931. Miembro de la comisión ejecutiva de la Federación Regional Socialista de Levante desde su congreso extraordinario de 1930, fue elegido concejal del Ayuntamiento eldense en las elecciones del 12 de abril de 1931, cargo que compaginó con el de presidente de la agrupación socialista de la vecina localidad de Petrer, en la que había fijado su residencia en 1930 para poner en práctica la cooperativa obrera de calzado El Faro.

\footnotetext{
13 Archivo Histórico General de la Defensa (AHGD), 15534/1, causa 80 de 1934.

${ }^{14}$ Lo hizo en el año 1927 con el nombre simbólico «Bebel». Centro Documental de la Memoria Histórica (en adelante CDMH)-TERMC-31744.
} 
Luis Arráez partía de experiencias cooperativistas anteriores, pues había sido uno de los impulsores de la construcción de viviendas para obreros y formación de sociedades de consumo desarrolladas en la Elda de los años 20. Pero el hecho de intentarlo ahora con una cooperativa de producción del principal ramo industrial de una comarca con importante conflictividad laboral y social, fue visto como una amenaza por algunos representantes de la patronal, que boicotearon la iniciativa con su influencia sobre entidades proveedoras y financieras, consiguiendo que cerraran sus puertas a El Faro. Sin embargo, con el esfuerzo de sus miembros cooperativistas, que en varias ocasiones renunciaron a sus salarios, la nueva cooperativa conseguiría abrirse al mercado nacional haciéndose un sitio entre las grandes industrias del calzado de la comarca. De hecho, compañeros del Partido Socialista en Madrid solicitaron copia de sus estatutos para poner en marcha una iniciativa similar. ${ }^{15}$

Pero de esta forma Luis Arráez conseguiría también ganarse la animadversión de los principales empresarios de la localidad de Petrer, que lo vieron como un competidor que robustecía la posición obrera en las conflictivas relaciones laborales. Entre ellos, quien había sido alcalde de la localidad durante la dictadura de Primo de Rivera: Luis Villaplana Reig, miembro fundador y principal accionista de Calzados Luvi S.A., una de las empresas más importantes del sector a escala nacional.

La conflictividad social y laboral que había detrás de los orígenes de El Faro quedó reflejada en la memoria de su primer año de funcionamiento, correspondiente al ejercicio de 1930. En la misma, el consejo de administración exponía las razones que llevaron a la constitución de la cooperativa:

Al calor de una contienda social, consecuencia del régimen capitalista, suscitó la idea a unos cuantos compañeros, de llegar a la constitución de una Cooperativa de producción que permitiera ir dando colocación a quienes, por su actuación constante en sentido de hacer frente a todas las injusticias sociales, veíanse perseguidos por los elementos de la burguesía.

La idea fue acogida con cariño; y aún dentro de las precarias condiciones en que la mayoría de los iniciadores se encontraban después de varias semanas de huelga, pusieron mano a la obra, dando comienzo a

15 CDMH, P.S. Madrid C-962 exp. 130. 
sus propósitos con la aportación de pequeñas cantidades que le permitieron confeccionar un muestrario. ${ }^{16}$

Por lo tanto, fue la conflictividad social y la situación concreta de varios trabajadores afiliados a la agrupación socialista y a la UGT a los que las fábricas de Petrer no daban trabajo como forma de represalia, lo que les llevó a secundar la iniciativa de Luis Arráez, que actuaría desde el principio como gerente.

Al cabo de su primer año de funcionamiento El Faro se había hecho un hueco importante en el mercado, por lo que sus crecientes pedidos permitieron la inversión en nueva maquinaria y la ampliación del local en el que desarrollaba su actividad productiva. Además, fueron adquiridos unos terrenos de más de treinta mil metros cuadrados destinados a construir una nueva fábrica y edificar viviendas para los obreros, también en régimen cooperativo, tal y como había quedado estipulado en el artículo adicional de sus estatutos. Todo ello sin dejar de atender a las necesidades de sus trabajadores, mediante subsidios por enfermedad, accidentes o incluso para aquellos que fueron encarcelados con motivo de los acontecimientos de diciembre de 1930.

Con el paso de los años El Faro llegaría a contar con más de doscientos cincuenta trabajadores y, tras una grave crisis, hubo de declarar suspensión de pagos en 1935, aunque sus mayores acreedores eran el propio Luis Arráez y resto de cooperativistas, que habían dejado de percibir sus salarios. La situación pudo retomarse al cambiar el nombre de la razón social, adquiriendo Luis Arráez su propiedad el 22 de noviembre de 1935, que se hizo cargo del embargo de los bienes y del pago de los salarios devengados. ${ }^{17}$ Todo cambiaría nueve meses después, cuando Luis Arráez hubo de dejar de lado su labor empresarial para ponerse al servicio del gobierno de la República en guerra.

En paralelo a su actividad cooperativista y empresarial, la promoción de Luis Arráez dentro de la Federación Provincial Socialista fue notoria, siendo uno de los hombres de máxima confianza de Rodolfo Llo-

${ }^{16}$ Memoria del ejercicio correspondiente al año de 1930 de la Cooperativa de producción El Faro, Industrias Gráficas Ortín, Elda, 1930.

${ }^{17}$ Escritura de venta y cancelación otorgada por Luis Amat Poveda y Vicente Beltrán Montesinos a Luis Arráez Martínez. Realizada ante el Notario de Monóvar Jesús Sancho Tello Latorre. Agradezco a Josefa Martí Arráez, nieta de Luis Arráez, que me haya facilitado copia de la misma. 
pis. ${ }^{18}$ Elegido concejal del Ayuntamiento de Elda en las elecciones del 12 de abril de 1931, tras sonar su nombre como posible candidato a diputado en Cortes tuvo un activo protagonismo en la campaña de las elecciones de febrero de 1936, participando en varios mítines dados en la provincia junto a Rodolfo Llopis. ${ }^{19}$ Sí fue elegido, con 144.071 sufragios, compromisario para la elección del presidente de la República por la circunscripción de Alicante en abril de $1936 .^{20}$ Tras el estallido de la rebelión militar, su profundo compromiso con la legalidad republicana le llevó a ocupar numerosos cargos de responsabilidad en la provincia de Alicante, como el de vocal del Comité Provincial de Incautación de Industrias, vocal suplente del Tribunal Popular y presidente de la Diputación Provincial entre el 5 de octubre y el 10 de diciembre de 1936, día en el que dimitió al ser nombrado gobernador civil de Málaga a propuesta del Gobierno de Largo Caballero. ${ }^{21}$ La labor desarrollada a cargo del mismo fue breve pero intensa, enfocada principalmente a robustecer la autoridad del Gobierno, fundamentalmente en relación a la recuperación del control del orden público y la organización de la copiosa acogida de refugiados llegados desde esta y otras provincias. Intensificó también las relaciones diplomáticas con continuas reuniones con los distintos cónsules y visitó en varias ocasiones el frente para arengar a las tropas, donde se vivía una frenética actividad ante el empuje rebelde iniciado el 17 de enero. ${ }^{22}$ No abandonó Málaga hasta el mismo 7 de febrero, después de que lo hubiera hecho precipitadamente el Estado Mayor del Coronel Villalba sin que le fuera notificado oficialmente, de lo que se quejó amargamente al no haberse contado con él para programar las tareas de una evacuación que resultaría caótica y desastrosa para la población civil. ${ }^{23}$ Tras

${ }^{18}$ Luis Arráez se encontraba entre un reducido grupo de hombres de máxima confianza dentro la Federación Provincial de Alicante. En carta del 4 de diciembre de 1938, en la que Rodolfo Llopis informaba de la situación de la guerra y de la Ejecutiva Nacional del PSOE, decía que sólo debían conocer dicha información «Arráez, Lizón y Deltell más Ferrándiz, aparte, claro, está Manolo que ya lo sabe y Ganga». CDMH-PS Alicante, Leg. 83/3

${ }^{19}$ La información puede seguirse en el semanario Rebelión, órgano de la Agrupación Socialista de Elda.

${ }^{20}$ CDMH-PS Barcelona, C300.

21 Gaceta de la República, 15 de diciembre de 1936.

22 Puede seguirse la actuación de Luis Arráez al frente del Gobierno Civil en las páginas de El Popular de Málaga entre el 17 de diciembre de 1936 y el 7 de febrero de 1937.

${ }^{23}$ Así lo testificó el jefe de la Comandancia Militar de la Base Naval, Baudilio San Martín, en la causa seguida contra el coronel José Villalba por la caída de Málaga. Un resumen oficial de la misma en Antonio Nadal, Guerra civil en Málaga, Arguval, Málaga, 1985, pp. 427-436. 
la caída de la capital andaluza en manos de las tropas rebeldes y colaborar junto al Gobierno Civil de Almería en las tareas de evacuación y acogida de refugiados, fue elegido secretario general de la Federación Provincial Socialista de Alicante en junio de 1937, cargo que desempeñó hasta marzo de 1938, cuando fue designado comisario del CRIM n. ${ }^{\circ} 10$ y Batallón de Retaguardia n. ${ }^{\circ} 6$ de Alicante, donde permanecería hasta el final mismo de la guerra, consciente de su responsabilidad en las tareas de evacuación del resto de militantes y mandos del ejército republicano. ${ }^{24} \mathrm{Su}$ sentido de la responsabilidad le llevó a esperar hasta el último momento para embarcar junto a su compañero y amigo, el diputado socialista Miguel Villalta, renunciando a marchar en el Stanbrook. Ambos tenían previsto hacerlo en el Maritime, último barco que partió hacia el exilio desde el puerto de Alicante la madrugada del 29 de marzo con tan solo 32 refugiados, dejando al resto abandonados a su suerte.

\section{Competencia desleal: denuncia, persecución y captura}

Miguel Villalta dio cuenta de lo que ocurrió a partir de ese momento en un Informe de situación que escribió en el Reformatorio de Adultos de Alicante tras ser detenido:

...Cuando llegamos al puerto nos encontramos con que la escalerilla estaba a medio levantar y que no dejaban subir a las treinta o cuarenta personas que escasamente había allí...Arráez y yo, tras varias peripecias, entramos en Villa Marco, término de San Juan, donde Zaragoza, Canciller del Consulado Argentino nos introdujo a ver al Sr. Barrera, quien nos admitió por unos días... le pedimos que nos amparara a través de la persona que medió con el Sr. Zaragoza la primera vez, y en vista de su negativa, a las 7 de la mañana del día primero de Abril, Arráez y yo nos separamos. ${ }^{25}$

En el «día de la victoria», sin otra posible salida, Luis Arráez y Miguel Villalta decidieron refugiarse en sus localidades de origen, yendo respectivamente a Elda y Monóvar. Desde ese momento Luis Arráez es-

24 CDMH-SM C1248 Exp. 62.

25 Glicerio Sánchez Recio, La república decapitada. El caso de la familia Villalta Gisbert (Alicante, 1939-1942), Flor del Viento, Barcelona, 2010, pp.140-141. 
tuvo ocultándose en casa de sus familiares, haciendo traslados cada cierto tiempo para mayor seguridad. Mientras tanto, su hermano Antonio y sus dos cuñados, Amador Milán López y Francisco Payá Santos, fueron detenidos, interrogados por su paradero y procesados. ${ }^{26}$

La preocupación por el destino de quienes no habían conseguido salir se hizo patente desde los primeros momentos. El mismo 3 de abril, Rodolfo Llopis escribiría a Luis Deltell, recién llegado a Argelia, mostrando su honda preocupación:

No necesito decirte la alegría que me produjo saber que os encontrabais en Beni-Saf, pues acababa de tener carta de Lizón anunciándome que no habíais podido tomar el vapor y que se temía por vuestra suerte. Lo de Arráez, Villalta y Caballero, me aterra. Y no digamos lo que haya podido suceder con tantos y tantos compañeros más. Se pone uno a pensar en amigos y es para horrorizarse... ${ }^{27}$

Luis Arráez estuvo escondido hasta el mes de diciembre de 1939, momento en el que decidió viajar a Málaga, donde Josefina Gálvez (esposa del aviador Carlos Haya, combatiente rebelde y piloto personal de Franco), se había comprometido a ayudarlo en agradecimiento al trato y protección que le había dispensado cuando la tuvo bajo su responsabilidad como prisionera en el Gobierno Civil de Málaga. Desde allí la condujo hasta Valencia, entregándola a salvo el día 10 de febrero de 1937 tras haber tenido varios enfrentamientos durante el trayecto con milicianos de la FAI que pretendían hacerse con la prisionera. Aun en calidad de tal, el ministro Ángel Galarza le proporcionó un volante con un nombre falso, Carmen de la Torre Vidal, con el que se alojó en el Hotel Victoria y, con escolta, pudo moverse con relativa libertad por la ciudad. ${ }^{28}$ En ese momento y por mediación del Comité de la Cruz Roja Internacional, el Gobierno de la República negociaba su canje, que finalmente se realizaría por Arthur

${ }^{26}$ Fueron condenados respectivamente a veinte, doce y doce años de prisión. AHGD, 16039/1, causa 7354; 15547/12, causa 7477; 15492/11, causa 1087.

27 Bruno Vargas y Francisco Moreno Sáez (eds.), Dramas de refugiado: Epistolario de Rodolfo Llopis y otros dirigentes socialistas alicantinos (1939-1947). Fundación Instituto de Historia Social, Valencia, 2007, pp. 41-42. Luis Deltell era secretario general de la UGT alicantina.

${ }^{28}$ Carmen de la Torre era el nombre de una cuñada de Josefina Gálvez. Agradezco a su hija Mirentxu Haya Gálvez que me haya proporcionado esta información y copia de la cédula que el ministro Galarza entregó a su madre. 
Koestler a través de Gibraltar, lugar por el que también intentaría salir de España Luis Arráez. ${ }^{29}$

El día previsto para viajar a La Línea quedó fijado para la mañana del 19 de diciembre de 1939. Fue allí donde, provisto de la cédula personal y el salvoconducto del chófer de la señora Gálvez para pasar a Gibraltar, fue descubierto y detenido por agentes del cuerpo de policía e inspección de la Frontera Sur. En su informe al director general de seguridad, el delegado de orden público detalló cómo se llevó a cabo la detención. Al parecer, alguien había puesto sobre aviso a la policía de frontera:

Por confidencias sabía esta Delegación que Luis Arráez Martínez, Gobernador Civil de Málaga en la última etapa roja, pretendía pasar la frontera de Gibraltar.

Montado un servicio especial de vigilancia por funcionarios del cuerpo de investigación y vigilancia que con gran actividad y celo se mantuvo durante dos días, dio por resultado la detención del anteriormente citado Luis Arráez. ${ }^{30}$

Por lo tanto, parece que las intenciones de Luis Arráez habían sido puestas en conocimiento de la Dirección General de Seguridad, lo que hizo más fácil que los agentes pudieran reconocerlo durante el interrogatorio al que fue sometido cuando trataba de cruzar la frontera. ${ }^{31}$ Pero en realidad Luis Arráez estaba en busca y captura desde hacía tiempo, pues su proceso sumarísimo se había incoado a finales de agosto, consecuencia de una denuncia presentada por Luis Villaplana. Precisamente, un hermano de éste, también miembro fundador y socio de Calzados Luvi, Ricardo Villaplana, denunciaría a Antonio Arráez Martínez, quien se había hecho cargo de gestionar El Faro durante los años de la guerra civil, señalando que era «hermano de Luis, último gobernador rojo de Málaga, de arraigadas tendencias marxistas y figura destacada del Socialismo.» ${ }^{32}$

${ }_{29}$ Marcel Junod, El tercer combatiente, CICR, Ginebra, 1985. (Ed. orig. 1947); Arthur Koestler, Memorias, Lumen, Barcelona, 2011. (ed. orig. 1954). He reconstruido el proceso de canje en mi tesis doctoral Ni paz, ni piedad, ni perdón. La guerra después de la guerra y la erradicación del enemigo en el partido judicial de Monóvar: la responsabilidad compartida (1939-1945). Tesis doctoral inédita, Universidad de Alicante, 2013, pp. 450-454.

30 Archivo General de la Administración, 44/10412.

31 AHGD, 15797/13, causa 6012.

32 En su declaración de ratificación, con Luis Arráez ya detenido, insistió en que Antonio Arráez era «hermano del tristemente célebre dirigente rojo Luis Arráez Martínez». AHGD, 16039/1, causa 7354. 
Una semana antes de su detención también se había incoado su expediente de Responsabilidades Políticas. En este caso, la denuncia fue formulada desde la alcaldía de Petrer, pero estaba firmada por el primer teniente de alcalde, Manuel Villaplana, hermano de los anteriores denunciantes:

En el tablón de anuncios de este juzgado municipal y en el BOPA n. ${ }^{\circ} 188$ de 2 de los corrientes, aparece edicto del juzgado de $1 .^{\mathrm{a}}$ instancia de Monóvar, en el que en virtud de autos de quiebra de D. Luis Arráez Martínez, se saca a pública subasta bienes inventariados del mismo, existentes en su fábrica de calzado de esta villa, por valor de 105.726'50 pesetas... y como el individuo de que se trata durante la dominación roja y antes de la guerra era uno de los dirigentes marxistas, habiendo desempeñado con motivo del GMN y en su contra, los cargos de Gobernador Civil de Málaga y Comisario Político en Alicante, me permitió poner en el superior conocimiento de VS el referido asunto por si considera de responsabilidad al quebrado y cree conveniente en tal caso ordenar la suspensión del procedimiento judicial de quiebra que se le sigue, con el fin de que dichos bienes sean incautados por el Estado a las resultas de las sanciones que puedan derivarse de sus actuaciones políticas. ${ }^{33}$

En realidad, esta denuncia tenía como objetivo apropiarse de El Faro, lo que las nuevas autoridades ya habían intentado en septiembre por otros medios. Así se hizo desde la Delegación Local de Sindicatos, cuando aprovechando la campaña de «desaparición del paro obrero» que había orquestado la Delegación Provincial, trataron de convencer a sus dirigentes de la utilidad que supondría hacerse con la fábrica de Luis Arráez:

En esta localidad existe una fábrica de calzado que perteneció en un principio a una Cooperativa Obrera Socialista, denominada 'El Faro'; por un mal asunto comercial a mediados de 1935, se hizo cargo de la misma por cesión de los accionistas un sujeto llamado Luis Arráez Martínez, individuo este reclamado por la Justicia, pues entre los muchos cargos que ostentó durante la dominación marxista está el de Gobernador Civil de Málaga, hasta que esta capital fue liberada, y hoy se ignora su paradero, como es consiguiente esta fábrica está cerrada, y sus obreros, unos 250 , en paro forzoso por lo tanto si esta fábrica se movilizase, el problema del paro sería fácilmente resuelto en esta plaza, pero si con-

33 Archivo Municipal Monóvar (AMM)-Responsabilidades Políticas. 
tinúa cerrada, veo difícil el acoplamiento de unos 400 obreros de esta industria parados... por todo ello interesa muchísimo, en bien de esta plaza y de España, procures si posible es, se ceda la maquinaria y enseres a esta delegación local y ya procuraríamos gestionar un socio capitalista para movilizar esta fábrica que tiene en la miseria a un buen número de familias. ${ }^{34}$

Lo que sucedió finalmente es que se abrió un tercer proceso contra Luis Arráez. En este caso de responsabilidad civil, por el que se expropiaban y pasaban a pública subasta los bienes de El Faro, tras dictaminar que había sido «abandonada» por su dueño tras la guerra civil. ${ }^{35}$

\section{La hora de la venganza: matar informando}

Luis Villaplana había puesto la denuncia contra Luis Arráez ante el sargento Arcadio Sánchez el 30 de agosto de 1939. Tras señalarlo como responsable de los acontecimientos desarrollados en octubre de 1934 en Petrer, siguió con valoraciones personales con las que trataba de describir su trayectoria política, para concluir con lo que sabía que era el cargo que podía hacerle más daño:

Que también le consta que es un individuo peligroso para la Causa Nacional, de bastante cultura y fácil palabra de la que se vale en mítines y asambleas para hacer propaganda a favor de la causa roja... principal responsable de las detenciones, incendios de iglesias y todas las canalladas que cometieron los rojos en Petrer durante su estancia. Que también fue nombrado Gobernador rojo de Málaga, cargo que desempeñaba cuando éstos la perdieron. También desempeñó el cargo de comisario político, secretario general de la UGT de Alicante, presidente de la Diputación Provincial de dicha capital, agente de vigilancia, y el principal responsable de los nueve fusilados de Petrer en Alicante el día diecisiete de octubre del treinta y seis, como miembro del tribunal popular de dicha capital en el que tenía gran influencia. ${ }^{36}$

\footnotetext{
34 Archivo Municipal Petrer. Legajos varios.

35 La causa fue seguida en el Juzgado de Primera Instancia e Instrucción de Monóvar. Archivo de la familia Arráez García.

${ }^{36}$ En realidad fueron ocho los vecinos de Petrer condenados a muerte y ejecutados, pero en la denuncia e informes las autoridades incluyeron siempre a un vecino de Rojales. Todas las citas que se harán del sumario en AHGD, 15797/13, causa 612.
} 
Luis Villaplana acudió acompañado de un empleado de su fábrica: el encargado general José García Reig, que también firmó la denuncia añadiendo descalificaciones personales que trataban de hacer más abyecta la figura de Luis Arráez:

...que hace que conoce a Luis Arráez Martínez, más de veinte años, y siempre lo ha visto militando en el partido socialista, como uno de los dirigentes, el que tenía mucha influencia, por su don de palabra fácil al embaucamiento de los obreros. Que el citado Arráez hace que trasladó su residencia a Petrel, sobre seis o siete años, y tan pronto como llegó tomó la dirección del partido socialista y UGT y todo lo que se ha hecho de malo en dicho partido y sindical es el principal responsable. Que tan pronto como se inició el Glorioso Movimiento Nacional, se personó en el Ayuntamiento, dando órdenes a los rojos, para practicar detenciones, verificar incendios, requisas y otras canalladas, como presidente del Frente Popular y comité antifascista... que fue el principal inductor de los nueve fusilados de Petrel en Alicante, como miembro del tribunal popular de dicha capital, diciendo a los familiares de las víctimas de Petrel, que los que quedaran con vida después del triunfo marxista, tendrían envidia de los muertos.

Las noticias de la detención de Luis Arráez llegaron a Petrer un día después de llevarse a cabo, siendo comunicada al sargento Arcadio Sánchez junto a unas fotografías que aseguraban su identidad. Tras cerciorarse de que el prisionero le sería entregado convenientemente, pese a que Petrer contaba únicamente con un retén municipal, hasta el día 27 de diciembre no lo puso en conocimiento del juez, que dos días después llamó a declarar a los denunciantes para que se ratificaran. Ese día recibiría también los preceptivos informes de las autoridades locales.

Pero Arcadio Sánchez sería ascendido a brigada y destinado como comandante al puesto de la localidad de Monóvar dos días después, no pudiéndose hacer cargo del prisionero como había pretendido. Además, varias eventualidades imposibilitarían el traslado de Luis Arráez hasta el 17 de enero de 1940, siendo finalmente entregado en el Reformatorio de Adultos de Alicante la tarde del 19. Este retraso no impidió, sin embargo, que las autoridades de Petrer se hicieran cargo del prisionero dos días después, cuando les fue confiado para que prestara declaración ante el juez de instrucción. Este hecho significó una clara irregularidad, pues cuando los procesados eran trasladados para prestar declaración ingresaban en el Campo Penitenciario de Monóvar o en la cárcel de partido 
de Novelda, pero en ningún caso en los depósitos municipales, lo que era especialmente grave al tratarse de un prisionero de la importancia de Luis Arráez, sobre quien el juez dictó un auto de incomunicación que lo mantendría en tal situación durante tres meses, hasta una semana antes de la celebración del Consejo de Guerra. Sin embargo, las lógicas locales demandaban otro tipo de medidas, y así fueron respetadas y correspondidas. ${ }^{37}$

Dolores Arráez presenció parte de lo que ocurrió aquellos días. Tras dar una explicación de lo que en la familia han pensado siempre acerca de los motivos de la especial inquina que en aquella localidad se tenía hacia su padre, evita hablar de los detalles de unos momentos muy dolorosos para ella:

En Petrer es que han sido muy malos con mi padre. Le tenían mucha envidia por haber creado la cooperativa de calzados El Faro. Él, primero fundó la de Elda, la cooperativa de casas baratas. Pero en Petrer fue lo peor. Fue la inquina por lo de la cooperativa... Yo estaba aquí en Málaga cuando se fue con Josefina Gálvez. Pero cuando me enteré de que a mi padre lo habían detenido me fui a Elda. Los de Petrer lo reclamaron y lo maltrataron todo lo que pudieron. Fue un cachondeo lo que hicieron por las calles con él. Fue un sacrilegio, vaya, y por eso nunca he querido volver a Petrer, nunca. ${ }^{38}$

Un vecino de la localidad, Tomás Jover Andreu, nos da más detalles de lo que hicieron con Luis Arráez por las calles de Petrer:

Luis Arráez fue localizado cuando se quería marchar por Algeciras, pero alguien lo delató y fue detenido, y como aquí en Petrer la derecha le tenía tantas ganas, saltándose todas las leyes jurisdiccionales, lo trajeron aquí al pueblo para mofarse de él y lo pasearon por las calles hasta la plaza de la iglesia, y allí le hicieron leer todos los nombres de los «caídos por España» que estaban escritos en la pared de la iglesia. ${ }^{39}$

37 AHGD, 15797/13, causa 6012; Archivo Histórico Provincial de Alicante (AHPA)IP-Expediente penitenciario de Luis Arráez.

38 Testimonio de Dolores Arráez García. Entrevista realizada en Málaga, 8 de octubre de 2005.

39 Testimonio de Tomás Jover Andreu. Entrevista realizada en Petrer, noviembre de 2002. 
Aunque Luis Arráez declaró ante el juez un día después de ser entregado a las autoridades de Petrer, aún permaneció en la misma durante otros tres días, siendo finalmente conducido al Campo Penitenciario de Monóvar en régimen de incomunicación el 25 de enero. Allí estuvo hasta el 12 de febrero, cuando fue definitivamente trasladado a la sección de periodos del Reformatorio de Adultos por orden del gobernador civil, al considerar que la prisión de Monóvar no presentaba las debidas condiciones de «rigurosa incomunicación». ${ }^{40}$ Nada sabemos sobre los tratos a los que Luis Arráez pudo haber sido sometido durante los cinco días que pasó en el depósito municipal de Petrer, sencillamente porque nadie pudo verlo hasta el 10 de abril, cuando fue levantado su régimen de incomunicación.

En sus declaraciones de ratificación los denunciantes fueron completando el conjunto de cargos que se perfilaría contra Luis Arráez. Luis Villaplana insistió en la supuesta presión que había ejercido sobre el Tribunal Popular, asegurando que «se encontraba presente, coaccionando a todo el tribunal, para que fuesen en lugar de nueve, veintisiete los asesinados» y lo consideró «responsable de todo lo que ocurrió, no ya en Petrer y Elda, sino en otros pueblos, en donde él también ejercía presión.» Algo en lo que insistiría José García, al hacerlo «responsable de la mayoría de las libertades ficticias que se condecían a los presos que más tarde aparecían asesinados en las carreteras... y exaltaba a los individuos de izquierda a que no entregaran a ningún preso, sino que los asesinaran.»

Por su parte, el alcalde Nicolás Andreu quiso completar esta imagen enviando un amplio informe del que es fácil inferir los verdaderos motivos del odio que prominentes vecinos de la localidad sentían hacia Luis Arráez:

Destacado marxista, ha sido durante la guerra y antes del Glorioso Movimiento Nacional, uno de los dirigentes más eficaces de la masa obrera, imprimiendo constantemente en esta villa su acción socialista de cuyo partido era jefe local, con frecuentes propagandas escritas y actos públicos perturbadores del orden y marcha progresiva del trabajo en fábricas y talleres, donde con excusas de mejoras obreras (siendo el fin puramente político) motivaba frecuentes huelgas, que promovían los que ciegamente obedecían sus órdenes, considerándole por tanto el

40 AHPA-GC-1058. 
principal responsable de daños morales y materiales causados en la población y de muchísimas personas que han sufrido los extremados rigores de la dominación marxista...

Tras desvelar los verdaderos motivos que habían dado lugar a la persecución de Luis Arráez, pasaba a enumerar los que sabía que acabarían con su vida, y que nada tenían que ver con los anteriores:

...igualmente se le considera autor de las denuncias falsas contra inocentes, que en época de guerra originaron el fusilamiento en Alicante, el 17 de octubre de 1936, de nueve personas honorables de la localidad.

Además, me permito hacer constar que el individuo de que se trata, por su personalidad y preponderancia político-social como también su significación Marxista, ha desempeñado durante la época de mando Rojo, los cargos de... siendo su actuación y labor realizada al frente de dichos cargos nefasta y perturbadora para el engrandecimiento de la Patria, mereciendo por ello acerbas censuras y la más enérgica protesta de todos los buenos ciudadanos que desean la prosperidad de España.

El falangista Mariano Segura, en ese momento alcalde de Elda, también emitiría un informe cargado de descalificativos en el que, además, se atrevía a aventurar su actuación como gobernador civil de Málaga mediante deducciones al uso:

Ya en tiempos de la dictadura del general Primo de Rivera hizo propagandas izquierdistas y con gran celo trabajó para imponerse y hacer su hueco correspondiente para cuando llegase el triunfo de los suyos. Al advenimiento de la República vivió a sus anchas, tomando parte en mítines y otras manifestaciones de carácter rojo, lo que le valió el ser elegido concejal de este Ayuntamiento. Abominó siempre de cuanto significase orden y religión, puesto que formó parte de la logia masónica de esta ciudad. Su actuación como gobernador civil de Málaga, durante el periodo rojo, es en parte ignorada; más consta que indujo, como buen gobernante rojo, a la comisión de asesinatos y toda clase de hechos delictivos.

En realidad, y siguiendo la política llevada a cabo por sus antecesores, Luis Arráez trató en todo momento de controlar el orden público enfrentándose a los milicianos de la CNT-FAI, que ejercieron una enorme 
presión. ${ }^{41}$ Así lo supieron reconocer las propias autoridades malagueñas cuando constataron en sus informes que «creó una patrulla en esta localidad, con objeto de evitar los llamados paseos» y evitó la saca de presos al trasladarlos «a un buque prisión donde, aunque recibieron peor trato que en la cárcel, se evitaba mejor que el populacho lo asaltase.. ${ }^{42}$

Además, el mismo 16 de diciembre de 1936 y tras tomar posesión de su cargo, se entrevistó con el ya destituido cónsul de México en Málaga, Porfirio Smerdou, manifestándole que pese a la imposibilidad de reconocer los derechos de asilo del Consulado, podía continuar con su labor humanitaria, que permitió salvar la vida a varios refugiados en Villa Maya, sede consular. ${ }^{43}$

41 Antonio Nadal, op. cit., pp. 133-136. Según información dada por un evadido en diciembre de 1936 «La FAI está muy disgustada con los demás partidos, habiendo intentado apoderarse del Gobierno Civil, pero no pudieron. Hace cuestión de un mes el Gobernador ordenó desarmar a la FAI... no consiente que maten a nadie». AGMA-Arm. 18, Leg. 6, Carp. 26.

42 Informes del Gobierno Civil, Guardia Civil y Jefatura Provincial de FET-JONS de Málaga, días 23 y 30 de enero y 26 de febrero de 1940. AHGD, 15797/13, causa 6012. De hecho, una de las primeras medidas que tomó respondía al impulso dado por el Gobierno de Largo Caballero para imponer su autoridad sobre todo tipo de consejos y comités y devolver así el control del orden público a la autoridad gubernativa. Tras convocar y entrevistarse con los representantes de los partidos del Frente Popular y sindicatos obreros y dejar clara su posición, dirigió una enérgica circular a todos los alcaldes de la provincia por la que ordenaba cesaran completamente todos los servicios de control y vigilancia que no dependieran directamente de su autoridad:

«Por el ministerio de la Gobernación se han dado órdenes en ocasiones distintas para que desparezcan de las carreteras los controles establecidos por Comités y partidos políticos o sindicales. Ello no obstante, y aun cuando en muy escasa cantidad, continúan algunos controles de esta naturaleza... Por ello, haciendo uso de las atribuciones que me han sido conferidas, vengo en ordenar lo siguiente:

A partir de esta fecha se suprimirán todos los controles existentes en carreteras y entradas de población que hayan sido establecidos por Consejos de Defensa, Comités o por los partidos políticos u organizaciones sindicales. Todo control o vigilancia que a partir de esta orden subsistiera, contraviniéndola, será inmediatamente impedida por la autoridad gubernativa, y los individuos que se resistieran serán detenidos y puestos a disposición de la autoridad judicial para ser juzgados. Cuando por necesidades de guerra la autoridad militar estimara necesario el establecimiento de algún control especial, éste deberá ser ejercido por fuerzas militares debidamente controladas o en su defecto por individuos de este Gobierno civil que posean carnets firmados por mí.

Málaga 28 de diciembre de 1936. El gobernador civil, Luis Arráez Martínez.» El Popular, AÑO XXXIV, n. $^{\circ}$ 7282, martes 29 de diciembre de 1936. Archivo Díaz Escobar.

${ }^{43}$ Fundación Ortega y Gasset, Archivo Porfirio Smerdou; Antonio Manuel Moral Roncal, «El asilo consular en Málaga (1936-1937): La gestión diplomática de Porfirio Smerduo», Jábega, n. ${ }^{\circ}$ 91, 2002, pp. 103-115. 
El juez instructor tomó declaración indagatoria a Luis Arráez el 22 de enero de 1940, la que debió ser larga y de gran intensidad, pues hubo de suspenderla «por lo avanzado de la hora», destacando la tendenciosidad de unas preguntas que originaban que Luis Arráez tuviera que realizar afirmaciones como «que durante su mandato en Málaga se cometieron algunos asesinatos. ${ }^{44}$ Ese mismo día comparecieron también los dieciséis informantes que declararon en su contra, diez familiares de «caídos», cinco empresarios del calzado otrora competidores de Luis Arráez y un enemigo personal: el brigada Arcadio Sánchez. Un estudio de las declaraciones sugiere que fueron aprendidas y recitadas, pues todas ellas presentan un mismo campo semántico (con significantes como orador de prestigio, dirigente influyente, alentador de masas, inductor de asesinatos) y una misma estructura gramatical, coincidiendo incluso en sus unidades y giros léxicos, independientemente del estatus social, edad, sexo y formación cultural de los mismos.

Carlo Ginzburg llamó la atención sobre un aspecto de las fuentes judiciales, al constatar las pérdidas que se producen en el paso de lo oral a lo escrito, tales como entonaciones, dudas, silencios o gestos. En este sentido, su libro sobre el juez y el historiador es un claro ejemplo de la distancia que se aloja entre lo que se dice y lo que se trascribe de un interrogatorio y un juicio oral. Para el historiador italiano «en tal caso la transcripción es ya interpretación y condiciona las interpretaciones sucesivas elaboradas en un futuro próximo.» ${ }^{45}$

Cabe, por tanto, la posibilidad de que, aunque no en su contenido, los informantes se expresaran de otra manera y que el lenguaje utilizado haya llegado distorsionado por el filtro de la homogeneidad que pudiera haber

${ }^{44}$ Aunque las preguntas del juez no son transcritas en el sumario, pueden inferirse de las respuestas de los procesados, muchas veces provocadas para que pareciera que decían lo que seguramente no querían decir y en las que destacan la ausencia de matices y las afirmaciones contundentes. Como ha escrito Carlo Ginzburg se trata de estar atentos a «las tensiones subterráneas que alteran la superficie del diálogo.» Carlo Ginzburg, El juez. y el historiador. Acotaciones al margen del caso Sofri, Anaya \& Mario Muchnik, Madrid, 1993 , p. 56.

45 Ibídem, p. 25. Algo mucho más grave es la distorsión de las manifestaciones del procesado. En este sentido, las fuentes judiciales se ven condicionadas por el papel jugado por quien es intermediario entre la fuente y el historiador: el juez que estructura y produce el documento y de cuyo interés en descubrir la verdad dependerá la calidad de los testimonios obtenidos para el historiador. Jan T. Cross, Vecinos. El exterminio de la comunidad judía de Jedwabne, Crítica, Barcelona, p. 41. 
aplicado quien realizaba la transcripción de sus declaraciones. Sin embargo, reducir la cuestión a un aspecto que no pasa de hipótesis significaría perder toda una serie de posibilidades de análisis del discurso que nos permite inferir otro tipo de consideraciones, como las relaciones entre la conducta de los informantes y los signos lingüísticos que utilizan. En este sentido, no se trata de que prestemos atención únicamente a los distintos giros léxicos con los que se deberían haber expresado - sin que lo hicieran - individuos de distintos estratos sociales, lo que, desde un punto de vista linguístico, podríamos llamar diferencias diastráticas. ${ }^{46}$ Sino que debemos prestar atención a los registros de habla diferentes; es decir, a las diferencias diafásicas y que hacen referencia a las existentes entre un uso retórico de la lengua propiciado por el poder, como hicieron autoridades e informantes, y un uso neutro, como solían hacer los pocos testigos presenciales o familiares de víctimas que no habían sido movilizados por las autoridades.

En este sentido, es importante constatar que la desaparición de las diferencias diastráticas y la confluencia de las diafásicas nos indican que el lenguaje ha dejado de ser un hecho espontáneo para transformarse en un caso de evidente manipulación lingüística. Si no había diferencias entre las declaraciones de los informantes de diverso género, cultura y edad, es porque las únicas que podemos hallar son las que existen entre la posibilidad de haber proferido un discurso neutro o uno retórico, que fue el que utilizaron los informantes contra Luis Arráez. Por lo tanto, el discurso retórico tenía una clara función: constatar los sentimientos malvados del procesado, de ahí que la mayoría de las acusaciones estuvieran acompañadas de descalificaciones hacia su persona, a la que consideraban: «de condiciones muy depravadas», «de muy baja condición moral», «de muy malos sentimientos», «siempre dispuesta a realizar el mal», «de aviesa intención», o «de refinada maldad». Además, se adaptaban a la relación que cada informante o autoridad tenía con los hechos violentos ocurridos en la localidad durante la guerra civil, como es el caso del cura párroco, Conrado Poveda, que en su informe para el juez de Responsabilidades Políticas, además de considerarlo «el principal culpable de los muertos habidos en esta villa por Dios y por la Patria», aseguraba que «dirigió la quema de la Iglesia y demás objetos pertenecientes a ella, siendo su domicilio depósito de los gases inflamables que emplearon. $\rangle^{47}$

46 Sobre estos conceptos José A. Pérez Bowie, El léxico de la muerte durante la guerra civil española (Ensayo de descripción), Universidad de Salamanca, 1983.

${ }^{47}$ AMM-Responsabilidades Políticas. 
Con este discurso, autoridades e informantes consiguieron elaborar una imagen tan abyecta de Luis Arráez que la fiscalía de guerra pidió para él tres penas de muerte y acabó calificándolo como «peligrosísimo por su monstruosidad reflejada en su actuación durante todo el periodo rojo.» ¿Creían todo lo que decían sobre él? Claramente, no. Lo conocían desde hacía años. Eran vecinos. Ricardo Villaplana vivía puerta con puerta de Luis Arráez, y el alcalde, Nicolás Andreu, lo hacía a escasos cincuenta metros, al doblar la esquina y enfrente de la fábrica El Faro. El objetivo era provocar en el destinatario del mensaje, la autoridad judicial militar, una reacción de repulsa que, a su vez, confirmara los estereotipos de la imagen que debía tener como «rojo», dado su importante pasado dentro del Partido Socialista y los muchos cargos de responsabilidad que ocupó durante la guerra civil, por lo que era considerado un enemigo a eliminar. De esta forma, el discurso estructurado desde el poder sobre la imagen del enemigo se retroalimentaba desde abajo en una relación de ida y vuelta. Las autoridades locales e informantes no lo habían elaborado, sólo debían demostrar que comulgaban con el mismo y confirmarlo en la persona del procesado, al que acusaban de ser responsable de la muerte de personas concretas. En este sentido, el discurso sobre las atrocidades del enemigo tenía un itinerario que iba de la propaganda y textos oficiales al ciudadano, y de éste, mediante informes y declaraciones, al cuerpo del sumario, ya que jueces de instrucción y ponentes de los consejos de guerra no hicieron otra cosa que reproducir en sus autos y sentencias las principales acusaciones que se realizaban contra los procesados.

Sobre estas consideraciones, cuando el juez presentó su auto resumen había sabido derivar responsabilidades criminales de la actuación de Luis Arráez en cada uno de sus cargos. Así, de su actuación en Petrer lo consideraba:

...responsable directo de cuantas detenciones, asesinatos, saqueos, robos y demás hechos delictivos que se cometieron en el indicado pueblo... llegando al extremo, debido a su prestigio político, de coaccionar a los componentes del Tribunal Popular Rojo de Alicante, cuando se celebró un juicio contra los encartados de derechas de Petrer, pretendiendo que todos fueran condenados a la última pena y para ello, formuló de antemano denuncia falsa, obligando a personas de Petrer, que ciegos creían en él, para que asistieran, como así lo efectuaron, como testigos falsos de cargo y por este procedimiento de coacción, consiguió que se condenara a muerte a nueve honradísimas personas de derechas de Petrer... 
Después de nombrar su elección como compromisario para la votación «del funesto Azaña», enjuiciaba así su labor en el CRIM y Batallón de Retaguardia de Alicante:

...informaba como tal comisario de la ideología de cada uno de los individuos que se veían obligados a incorporarse, alguno de los cuales, como consecuencia de estos informes fueron asesinados en el frente.

Respecto a su actuación como gobernador civil de Málaga, obviaba los informes que desde allí se habían recibido y reproducía fielmente las opiniones de los informantes de Petrer, asegurando además — tal y como mencionaba José García en su denuncia - que había formado parte «del Comité de Orden Público de Alicante, en el que se ordenaba y daba la conformidad para la extracción de presos de las cárceles para asesinarlos después en las carreteras.»

La imagen que se había construido de Luis Arráez era tal que, pese a las numerosas personas que en su declaración nombró haber protegido, se permitía acabar su auto resumen diciendo:

El refinamiento de maldad del inculpado Luis Arráez Martínez llegó hasta el extremo de decir en su declaración indagatoria que protegió y salvó la vida de doña Josefina Gálvez, viuda del Glorioso Capitán de la Aviación Nacional Sr. Haya... Manifiesta también en su indagatoria que por su intervención evitó la detención de varias personas y la libertad de otras, hecho este que no puede tomarse en consideración, debido a la calidad depravada y malos sentimientos del inculpado.

Luis Arráez hubo de enfrentarse también a sendos careos con seis familiares de los fusilados por sentencia del Tribunal Popular. Éstos habían sido convenientemente movilizados por las autoridades locales, que señalaron a Luis Arráez como principal responsable de que se fallara pena de muerte contra ocho de los treinta vecinos de Petrer que fueron procesados. ${ }^{48}$ En los careos, el juez permitió desaforadas declaraciones como la de Ana Brotons Payá, quien no encontró límites a su invectiva:

48 La complementariedad entre una comunidad de la muerte y una comunidad de castigo es una de las líneas interpretativas del trabajo de Gutmaro Gómez Bravo y Jorge Marco, La obra del miedo..., op. cit., p. 76; Ver también Peter Anderson y Miguel Ángel del Arco Blanco, «Construyendo la dictadura y castigando a sus enemigos. Represión y apoyos sociales del franquismo (1936-1951)», Historia Social, 71, 2011, pp. 125-141. 
...insiste enérgicamente en que, después de conocida en firme la sentencia a muerte dictada contra su hermano y ocho más, recurrió en tono suplicante y de rodillas al que era entonces Presidente de la Diputación de Alicante Luis Arráez Martínez para que intercediera en su favor ya que le consta de una manera cierta que con una sola indicación del referido Arráez era bastante para dejar sin efecto aquella infame sentencia contestándole el Arráez que no se preocupara que todavía los que quedaban sin condenar le tendrían envidia a aquellos que irremisiblemente había que fusilar. Al día siguiente de esta entrevista habiéndose recibido telegrama de indulto del entonces Presidente de la República el funesto Manuel Azaña la declarante volvió a rogarle de nuevo exhibiendo el telegrama y entonces el Arráez le dijo: que aquello no tenía importancia que el presidente no era nadie y que por tanto se les fusilaría aunque le conmutara la pena, pues para él eso no valía nada y que aunque viniera el Gobierno en pleno se fusilaría a los condenados a muerte. Que entonces la declarante ante las manifestaciones de Arráez dijo que no llevarían a efecto el fusilamiento del malogrado y siempre llorando José Antonio Primo de Rivera y el Arráez le dijo con risa irónica que en la próxima semana lo haría. ${ }^{49}$

Terminado el careo, el juez no dudó en concluir, como en el resto de los llevados a cabo, «que D. ${ }^{a}$ Ana Brotons Payá dice más verdad, por la entereza y forma concreta y clara de contestar», lo que no era nada difícil, dada la asimetría de condiciones en las que se realizaron los careos. El desconcierto que debió sufrir Luis Arráez cuando presenció todas las injurias que se vertían sobre su persona y la gravedad de aquello de lo que pretendían responsabilizarle no podía sino afectarle de forma importante en su estado de equilibrio. Una mirada atenta a sus firmas nos permite ver que la estampada en su declaración ante el juez es equilibrada y «seca», mientras que las realizadas durante las diligencias de careo - del mismo día 22- están emborronadas, posiblemente debido a sudor procedente de sus manos, ya que el resto de las firmas que aparecen en cada uno de los careos - las de juez, secretario e informantes son «secas».

Las imágenes trasmitidas desde el poder a través de los discursos sobre un enemigo que era caracterizado como criminal deshumanizaban a la persona sobre la que se concretaba, lo que facilitaba que fuera anulado

${ }^{49}$ La sentencia fue comunicada al Consejo de Ministros el mismo 14 de octubre de 1936, que dio su conformidad. CDMH, PS Alicante, Leg. 41/4. 
cualquier sentimiento de respeto y piedad por parte de quienes se hacían eco del mismo. Su supuesta inferioridad moral y su comportamiento criminal debían justiciar su eliminación, de ahí que todas las declaraciones que aparecen en el sumarísimo contra Luis Arráez se vieran acompañadas de descalificaciones personales y referencias a la naturaleza perversa de sus sentimientos..$^{50}$

\section{Una suprema indefensión: sentencia y ejecución}

Ante la gravedad de las acusaciones, Luis Arráez no tuvo ninguna posibilidad de preparar su defensa, ya que, como denunció al auditor por medio de una instancia y pliego de descargos, había estado en rigurosa incomunicación desde su detención hasta el 10 de abril, seis días antes de la celebración del Consejo de Guerra, «por la incomprensible actitud de algunas personas con respecto al exponente... privándome, por tanto, de los medios indispensables para poder buscarme los medios de defensa.» ${ }^{51}$

Llegó a darse el caso de que cuando el juez provincial de responsabilidades políticas se dirigió el 22 de marzo al Reformatorio de Adultos para leerle los cargos que sobre él pesaban, el director del mismo no lo autorizó por la rigurosa incomunicación que el juez había ordenado, pudiéndosela realizar finalmente el 8 de abril..$^{52}$ Una semana después, a las ocho de la mañana y junto a otras cinco personas, Luis Arráez salía del Reformatorio de Adultos camino del salón de plenos de la Diputación Provincial, el mismo lugar en el que años atrás había tomado la palabra como presidente. Ahora lo esperaba el Consejo de Guerra que había de condenarlo a muerte, cuya actuación daría comienzo a las nueve de la mañana.

Tras la exposición del fiscal, que le pidió tres penas de muerte, el alférez García Romeu hizo observar que su defendido estaba incurso en un delito de adhesión a la rebelión, calificándolo como una persona de «ideas netamente marxistas» $\mathrm{y}$ «una de las mayores figuras socialistas de la pro-

50 Como lo ha expresado Omer Bartov, la definición del enemigo como paso previo a la creación de la víctima ha sido uno de los factores explicativos más importantes de la violencia del siglo xx. Omer Bartov, «Defining ememies, Making Victims: Germans, Jews, and the Holocaust», American Historical Review, june 1998, pp. 771-816.

51 AHGD, 15797/13, causa 6012.

52 AMM-Responsabilidades Políticas. 
vincia». Por ello, considerando que había contraído indudables responsabilidades políticas, pero «que no se le puede considerar como un criminal», pedía cínicamente que no se le impusiera una pena irreparable.

Luis Arráez reingresó en el Reformatorio de Adultos a las doce y media de la mañana. Mientras tanto, el vocal ponente redactaba la sentencia. ${ }^{53}$ En ella se consideraba probado que había sido compromisario para la elección «del funesto Azaña», ${ }^{54}$ que durante su «mandato» como presidente del Comité Antifascista de Petrer se había cometido un asesinato y el incendio de la iglesia. En cuanto a su actuación como vocal suplente del Tribunal Popular, pretendió hacerlo aparecer como un miembro más del jurado que condenó a los vecinos de Petrer, al limitarse a indicar que «intervino en diversos juicios contra personas de orden que fueron condenadas a muerte y ejecutadas; negándose a interceder a favor de unos convecinos suyos que corrieron igual suerte.»

Ignorando los informes de las autoridades provinciales de Málaga, consideraba asimismo probado que «durante su actuación ocurrieron numerosos atropellos y diversos asesinatos de los que tenía conocimiento», 55 y finalmente, camuflando la información de los beneficios que había ocasionado, introdujo la referencia a los mismos dentro de un contexto que lo hacía sospechoso por haber intentado «huir al extranjero por vía marítima desde este puerto y al no conseguirlo trató de hacerlo por la Línea a Gibraltar ayudado al efecto por alguna persona de las muchas que favoreció durante la época roja.»

Debemos destacar que el vocal ponente eludió mencionar a Josefina Gálvez como la persona que había ayudado a Luis Arráez a intentar pasar a Gibraltar. Además de que se trataba de la viuda del capitán Haya, suponía una importante prueba de descargo, pues difícilmente alguien a quien se le hubiera dispensado maltrato o sido raptado, como decían los informes oficiales, habría tratado de ayudarlo después, como efectivamente hizo. Además, suponía una clara prueba de la verdadera forma de proceder de Luis Arráez en el desempeño de sus cargos.

${ }^{53}$ Las horas de entrada y salida del Reformatorio pueden seguirse en su expediente penitenciario. AHPA-IP-Expediente penitenciario de Luis Arráez Martínez.

54 Obsérvese la coincidencia en el calificativo utilizado por Ana Brotons Payá en su careo con Luis Arráez del día 22 de enero de 1940.

55 Obsérvese que este considerando es retorcidamente derivado de la forma tendenciosa en la que el juez había realizado el interrogatorio a Luis Arráez, haciendo parecer que se autoinculpaba, tal y como hemos mencionado más arriba. 
El Consejo de Guerra consideró que Luis Arráez había fomentado «la acción revolucionaria y resistencia de aquel régimen contra el Alzamiento Nacional al tiempo que participaba en la enconada persecución de personas adictas al mismo muchas de las cuales fueron vilmente asesinadas», por lo que concurrían los agravantes de «gran perversidad y enorme trascendencia de los hechos», lo que se traducía en una condena a muerte.

La revisión de la causa fue la única posibilidad que le quedó para poder argumentar su defensa, por lo que, con gran escasez de tiempo y medios, preparó un detallado pliego de descargo y reunió distintas declaraciones juradas con las que no sólo trataba de demostrar su inocencia, para lo que habría sido necesario ser juzgado con unas garantías procesales que eran inexistentes, sino desmontar cada una de las injurias de las que había sido objeto y «la falsedad de los sentimientos que se me atribuyen», defendiendo en todo momento su «honradez y rectitud de proceder.» ${ }^{56}$

Aun con la premura de tiempo, pudo conseguir varios testimonios favorables de vecinos de Málaga y de distintos municipios de la provincia de Alicante, incluida Elda, que certificaban los beneficios ocasionados y los daños evitados durante el desempeño de sus cargos. Personas de derechas y militantes de FET y de las JONS que reconocían la protección dada y el comportamiento que Luis Arráez había tenido en momentos muy desfavorables para ellos, considerándole «persona de gran caballerosidad, honrada y de buenos sentimientos, a pesar de sus ideas políticas, que exteriorizaba condenando toda violencia».57

No ocurrió así en Petrer, donde, entre las numerosas personas que favoreció, nadie estuvo dispuesto a declarar en su favor. Como recordaba su hija Pura, cuando iba a verlo al Reformatorio:

Mi padre nos decía que no nos preocupáramos. Recuerdo que le preguntaba a mi tía Anica si había ido a ver a tal y a cuál y mi tía le respondía que sí, pero que no le habían contestado. Yo percibía la preocupación de ambos. Un día mi tía le dijo: Luis, no quieren saber nada. ${ }^{58}$

\footnotetext{
56 Pliego de descargo enviado al auditor el 20 de abril de 1940.

57 En este sentido se expresaron los vecinos de Málaga Alfonso Conejo Caro, militante de FET-JONS y Eduardo Ortega García, empresario de la localidad andaluza. También lo hicieron los vecinos de Elda Ovidio Guarinos, Enrique Payá Testor y Antonio Maestre Sempere, y de Alicante, José María Ferre Bernabéu y Vicente Sapena Richart. AHGD, 15797/13, causa 6012 .

58 Testimonio de Purificación Arráez García. Entrevista realizada en Málaga, 8 de octubre de 2005.
} 
Era muy difícil que alguien de Petrer firmara una declaración a favor de Luis Arráez. La animadversión que hacia su figura había entre las autoridades y personas afectas al nuevo régimen se combinaba con el miedo a ser perseguidos que podían sentir todos aquellos sospechosos de haber estado próximos a su figura, llegándose al extremo de que el sargento Arcadio Sánchez preguntara a una detenida, en tono acusatorio, si era «la lavandera de la Sra. de Luis Arráez.» ${ }^{59}$

Dolores Arráez insistía en una idea que repitió varias veces a lo largo de nuestra entrevista:

En Elda no había problemas con la familia Arráez. Petrer fue horroroso, fue todo el daño que le hicieron por la fábrica que tenía mi padre, que hizo la cooperativa y les dio participación a todos los obreros y quería hacer las casas para los obreros allí donde estaban las casas baratas de Elda, que a continuación está Petrer. Pero los informes que dieron desde Petrer al juzgado fueron los que hicieron las malas cuentas. La gente de Petrer fueron los que dieron los malos informes, los que influyeron en el juzgado para que hicieran lo que hicieron. ${ }^{60}$

En la correspondencia que Luis Arráez mantuvo desde el Reformatorio de Adultos podemos observar que daba gran importancia a lo que pudieran hacer dos personas a las que había beneficiado años atrás y que no podía imaginar la influencia que estaban teniendo en su sumario: Luis Villaplana, que había puesto la denuncia, y Nicolás Andreu, que desde la alcaldía había elaborado un informe demoledor. Así, en una de las notas que pudo sacar entre la muda decía:

Los certificados que tengáis conviene que vayan unidos a la instancia, cosidos a la misma para que no sufran extravío, y como sabéis, es lo único que tiene alguna eficacia por lo que hay que hacerse con la mayor cantidad posible. Poner la póliza correspondiente y asesoraros bien de las cosas para que no haya sorpresas, pues los Villaplana y el alcalde son los que pueden evitar contratiempos, como ellos dicen, haciendo que nadie de allí dé malos informes cuando los pidan, ya que en justicia no tienen ningún motivo para perjudicarme. Y sí en cambio para lo contrario. ${ }^{61}$

\footnotetext{
59 AHGD, 15781/7, causa 3168.

60 Testimonio de Dolores Arráez García. Entrevista citada.

${ }^{61}$ Nota de Luis Arráez desde el Reformatorio de Adultos, sin fecha. Archivo de la Familia Arráez García. Agradezco a Montse Arráez que me haya facilitado copia de estos escritos.
} 
La misma Dolores Arráez confirma lo que se desprende de este escrito:

Él no perdía el ánimo. Estaba convencido de que iba a salir porque pensaba que había hecho mucho bien y todo el mundo le iba a responder. No pensaba que en Petrer lo querían tan mal. Nos decía que no nos preocupáramos. Estaba convencido de que iban a aportar todos buenos informes y no fue así, claro. Luego, un día fui yo con mi tía Anica a Petrer a casa de Colau que le llamaban, Colau era el alcalde de entonces, Nicolás Andreu. Dijo que sí, que harían, pero no hicieron nada. Al contrario, cuando lo llevaron a Petrer lo que hicieron fue maltratarlo todo lo que pudieron.

Efectivamente, en su pliego de descargo y en los apuntes con los que lo preparó desde el Reformatorio, Luis Arráez nos ofrece una visión muy distinta de lo ocurrido con los procesados de Petrer en 1936, en cuya denuncia y posterior condena nada tuvo que ver. Debemos tener en cuenta, además, que en el sumarísimo colectivo con el que se habían abordado tales hechos a partir del mismo abril de 1939 sólo salió a colación su nombre una vez: en las diligencias previas de Arcadio Sánchez y sin que volviera a aparecer a lo largo de sus cientos de páginas. ${ }^{62}$

Sus primeras anotaciones nos aclaran cuál fue su verdadero papel:

...debido a mi intervención se libraron de una muerte posible, Alfonso Chico, Luis y Ricardo Villaplana y de la segura condena de muerte, Santiago García, Manuel Villaplana, Nicolás Andreu, Pepe el de la agrícola, Sánchez el del juzgado y el «Ritoret», sobre los cuales pesaban muy malos informes del partido y debido a mi incesante intervención logré los renovaran grandemente a favor de los interesados, los que se libraron de la última pena. ${ }^{63}$

Así lo expuso en el pliego de descargo:

En esta misma época se celebró el juicio de los Sres. de Petrel en el que yo no tuve la menor participación, pues únicamente hice que pedir a los de mi partido, una vez que estuvieron a saludarme, que procuraran

62 AHGD, 15323/5, causa 2346-2936-1888-3888.

${ }^{63}$ Las cinco últimas personas que menciona fueron acusadas de un delito de rebelión ante el Tribunal Popular, sufriendo finalmente penas de prisión, como Santiago García, condenado a veinte años, o absolución, como el caso de Nicolás Andreu. 
por todos medios evitar que a nadie ocurriera nada irreparable prometiéndolo formalmente y me aseguraron que así lo harían con los procesados Manuel Villaplana, Santiago García, Pepe el de la Agrícola, Gabriel Sánchez y Nicolás Andreu, que los demás querían que fueran condenados a muerte y cuyos informes dependían de los de mi partido, pero que no sabían si podrían hacer lo mismo con los que dependían de otros sectores más exaltados, y por ello, a instancias mías modificaron el informe de los Sres. citados y el de Francisco Chico para que no les ocurriera nada irreparable. D. José Vidal, de Alicante, que formó conmigo parte de la Comisión Provincial de Industrias, puede atestiguar cómo me lamentara yo de las cosas que me enteraba pasaban en Petrer, en demostración de la falsedad de los sentimientos que se me atribuyen por algunas personas perjudicadas que, movidas por el odio y el rencor, muy disculpables, pero que no puede justificarse dirigido a quien, como yo, queda demostrado no tuvo la menor participación en ese daño y en cambio pude conseguir evitar los citados; por otra parte, las personas perjudicadas conocen perfectamente quienes fueron los causantes de aquellos hechos. ${ }^{64}$

Otra de las personas que Luis Arráez pensaba que le estaba ayudando era Santiago Piqueras, al que había protegido colocándolo como su secretario en el CRIM, pese a saber que era camisa vieja de Falange. Supuestamente, y como indicaba a sus hermanas, éste debía gestionar la obtención de varios avales de personas a las que había favorecido informando favorablemente desde el mismo y de cuyos nombres Santiago Piqueras debía acordarse mejor:

No dejéis de ver a los de Albatera, que Piqueras también los conoce, para reunir la mayor cantidad posible de avales y como Piqueras conoce a muchísimas personas de las que hicimos bien y que yo no me acuerdo, que no deje de recoger cuantos certificados puedan beneficiarme pues aun cuando sé que Piqueras lo hace con mucho gusto, espero le hagáis saber mi reconocimiento por su buen sentido de la gratitud. ${ }^{65}$

Pese a simular muy bien que lo intentaba, Santiago Piqueras no consiguió ningún aval. Los motivos eran desconocidos para Luis Arráez, que tampoco sabía que había prestado declaración ante el juez el 24 de enero, ni mucho menos el contenido de la misma:

64 AHGD, 15797/13, causa 6012.

65 Nota de Luis Arráez desde el Reformatorio de Adulos. Sin fecha. 
Que el declarante conoce a fondo su actuación como comisario en el CRIM por estar destinado en las oficinas del mismo y sabe que siempre se dedicaba a perseguir a los reclutas que suponía eran de derechas enviando información a las Brigadas donde iban destinados o entregándolos al SIM para su encarcelamiento.

Que siempre se ensañó con todos los elementos afectos a nuestro GMN considerándole responsable de todos los atropellos y asesinatos cometidos en los batallones disciplinarios en las personas que a ellos marchaban destinados desde Alicante. ${ }^{66}$

El 23 de abril, una semana después de su condena a muerte y tan sólo tres días desde que había escrito y enviado el pliego de descargo con el que trataba de argumentar su defensa, el auditor aprobó la sentencia. Luis Arráez era consciente de que le quedaba poco tiempo y como única vía la solicitud de indulto, por lo que pidió a su familia que insistieran sobre todas aquellas personas a las que había beneficiado y que no le estaban respondiendo como esperaba. Sabía que eran los únicos que podían actuar como contrapeso de quienes lo habían llevado a la situación en la que se encontraba, sin que intuyera que los verdaderos responsables lo conocían muy bien:

No dormirse para que no ocurra nada por sorpresa pues todos aquellos que intervengan en mi favor pueden tener la certeza de que yo podré tener una responsabilidad política pero de ninguna manera estoy salpicado de ninguna responsabilidad criminal.

Yo estoy tranquilo de mi honrada conducta, pero como no se puede evitar el odio de quienes, por no conocerme, tratan de perjudicarme, es necesario actuar activamente para anular los pasos de esos elementos, contrarrestándolos a tiempo con los innumerables casos en los que intervine a favor de la gente, buscando para cada caso, la persona que lo pueda conseguir. ${ }^{67}$

El 29 de junio de 1940 Luis Arráez firmaba la solicitud de indulto dirigida al jefe del Estado. No aportaba nada nuevo, pero es de destacar que en el punto dedicado a su actuación en Petrer, y en forma de síntesis, mencionara como personas a las que más había favorecido los nombres de «Luis y Ricardo Villaplana, Luis Maestre Beltrán, Nicolás An-

\footnotetext{
66 AHGD, 15797/13, causa 6012.

${ }^{67}$ Nota de Luis Arráez desde el Reformatorio de Adulos. Sin fecha.
} 
dreu, y otros, de Petrer, que escaparon sin daño gracias a mi decidida intervención.» ${ }^{68}$ El primero lo había denunciado, tal y como hizo el segundo con su hermano. Luis Maestre, también propietario de una fábrica de calzado, prestó declaración en su contra. Poco podemos añadir sobre el papel jugado por Nicolás Andreu.

El capitán general de Valencia declaró la sentencia firme y ejecutoria el 8 de julio, ordenando que fuera cumplida en el plazo improrrogable de ocho días. No se cumplieron. Luis Arráez Martínez fue fusilado el 12 de julio de 1940 a las cinco de la madrugada junto a los muros del campamento militar de Rabasa. Horas antes había entrado en la capilla del Reformatorio de Adultos. Allí escribió sus últimas palabras, dirigidas a su familia en una carta tan escueta como contundente:

Queridos hijos, esposa, hermanos y demás familia:

Al despedirme sólo quiero que tengáis en cuenta, aun cuando ello no sería necesario, que muero completamente tranquilo de no haber hecho daño a nadie y sí todo el bien que pude.

Como no hice por crearme enemigos, creí que nadie lo sería mío. Sed buenos y laboriosos y sabed que podéis ostentar honradamente el apellido que lleváis.

Muchos abrazos

Luis

Hoy, madrugada del 12-7-94069

Que sean sus últimas palabras adquiere una importancia muy significativa, pues era consciente de que con las innumerables injurias de las que había sido objeto durante todo el proceso de persecución, captura, sumarísimo y condena a muerte, habían intentado asesinar no sólo a la persona jurídica, sino a la moral, en un clima caracterizado por el profundo odio y las ansias de venganza que el Estado franquista supo canalizar a través de las instituciones civiles y militares para acabar con quienes habían sido declarados enemigos de la causa nacional. De acuerdo a la propaganda

68 Solicitud de indulto dirigida al Jefe del Estado, 29 de junio de 1940. Archivo de la familia Arráez García.

69 Archivo de la familia Arráez García. Con mi profundo agradecimiento a Dolores y Purificación Arráez, que me ofrecieron su tiempo y permitieron el acceso a la misma. In memoriam. 
que se había desarrollado al calor de la cultura de guerra, éstos debían ser presentados como peligrosos delincuentes movidos por los más bajos instintos, adecuando su imagen a la del rojo perverso. Así lo hicieron aquellos a los que Luis Arráez había disputado la preeminencia social y política en los años treinta, constituyéndose como el principal referente de la clase obrera en las localidades de Elda y Petrer. Y así lo recogió el juez cuando, en su auto resumen, destacó que los beneficios que había ocasionado no podían ser tenidos en cuenta, «debido a la calidad depravada y malos sentimientos del inculpado.»

\section{Conclusiones}

Al preguntarnos por la relación entre violencia y responsabilidad a partir de la actuación de individuos concretos, la reducción de escala nos ha permitido observar conexiones que en principio habrían pasado desapercibidas en otras más amplias. Es clara la responsabilidad contraída y compartida por los agentes locales que colaboraron con las autoridades judiciales en el resultado final del proceso seguido contra Luis Arráez Martínez. Al señalar y declarar sistemáticamente contra un vecino al que conocían desde hacía más de veinte años sabiendo las consecuencias que se derivarían de sus falaces informaciones, se erigieron en pieza clave del funcionamiento y aplicación de la justicia militar en el ámbito local. ${ }^{70}$ Conocían la lógica de funcionamiento de los procesos sumarísimos y los consejos de guerra, desde el tipo de delitos imputables hasta las circunstancias modificativas de la responsabilidad penal contempladas en el Código de Justicia Militar sobre las que se sustentaban las condenas a

${ }^{70}$ El estudio de la represión judicial franquista en el ámbito local nos muestra que fue el resultado de un proceso conjunto en el que intervinieron dos niveles de agencia - estatal y local- que se complementaron para llevar a cabo con éxito aplastante la operación de limpieza política que se inició el 18 de julio de 1936 con un alzamiento contra el Gobierno legítimo de la Segunda República, y que continuó hasta entrados los años cuarenta, tras la definitiva victoria rebelde el 1 de abril de 1939. Intercambiando información por violencia, los objetivos de la política estatal y las motivaciones de los colaboradores locales quedaron perfectamente complementados. Pedro Payá López, «Ningún político republicano fue indemne al castigo: la represión de los políticos locales», en Glicerio Sánchez Recio y Roque Moreno Fonseret (coord.) Aniquilación de la República y castigo a la lealtad. Publicaciones de la Universidad de Alicante, Alicante, 2015, pp. 169-221; Violencia y responsabilidad. La represión judicial franquista en el ámbito local. Publicaciones de la Universidad de Valencia, Valencia, en prensa. 
muerte; desde el lenguaje utilizado, amparando y proyectando los discursos justificativos elaborados por la propaganda, hasta la recluta y asesoramiento en las declaraciones de los familiares de las víctimas de la violencia en retaguardia. ${ }^{71}$

Precisamente, el lenguaje consensuado fue una de las herramientas más destacadas entre las utilizadas por los distintos agentes que intervinieron en el proceso para confirmar la imagen que se quería del procesado, en relación a estereotipos que agudizaban su despersonalización jurídica. Pero si en sus discursos sobre el enemigo las autoridades militares perseguían erradicar algo que trascendía la individualidad misma del procesado, visto como enemigo político total - el hostis teorizado por Carl Schmitt-, para los agentes locales era el inimicus, aquel que se reduce al campo de lo privado. ${ }^{72}$

El Estado conseguía acabar así con quien antes había definido como enemigo: el secretario general de los socialistas alicantinos y gobernador civil de Málaga. Las autoridades locales, en cambio, con el vecino incómodo a sus intereses: quien había sido rival político, defendido posiciones contrarias a intereses públicos o particulares, o encabezado los comités de huelga dentro de la conflictividad social y laboral de los años treinta. También aquel hacia el que se tenía una enemistad personal, o sencillamente quien desempeña una misma profesión al que ahora las circunstancias permitían hacerle una «competencia desleal». Violencia de Estado y venganza privada confluyeron para llevar a cabo la limpieza política que se había perseguido desde el 18 de julio de $1936 .^{73}$

71 Los agentes locales sabían que las autoridades militares no realizarían ninguna comprobación adicional, no dispuestos a investigar los cargos de los que eran acusados. En lugar de ello, era suficiente que el perfil del procesado se adecuara a los estereotipos del enemigo. Para la relación entre polarización general e información local en la selección de las víctimas de la violencia ver Stathis N. Kalivas, La lógica de la violencia en la guerra civil, Akal, Madrid, 2010, pp. 268-271.

72 Para Carl Schmitt la razón de ser del enemigo total reside en una hostilidad que es anterior y condición del enfrentamiento. Se trata del enemigo político - definido como tal por el Estado-, con quien se tiene un enfrentamiento público y al que no hace falta odiar personalmente, pues el enemigo no es sino una comunidad de personas a la que se debe combatir por otra comunidad constituida de forma beligerante como tal. Esta es la diferencia entre hostis, enemigo público, e inimicus, aquel que se reduce al campo de lo privado y está motivado por razones como la competencia y sentimientos como la antipatía y el odio. Carl Schmitt, El concepto de lo político. Madrid, Alianza, 1991, pp. 58-59.

${ }^{73}$ En su trabajo sobre la colaboración de las autoridades locales polacas durante la ocupación por la URSS, Jan T. Gross concluye que se produjo una auténtica privatización 
No importaba, pues, la verdad, quién era y cuál había sido la actuación de Luis Arráez en el desempeño de sus innumerables cargos de responsabilidad, sino impartir «justicia»: La justicia de Franco, cuyo objetivo fue descabezar la República, erradicar al enemigo político allí, en cada localidad, confiando el control de las mismas a los nuevos pilares del régimen. Y Luis Arráez sería lo que estos dijeran. Así, si el cura párroco, Conrado Poveda, lo presentó como «un malversador de fondos» que había dirigido la quema de la iglesia, el sargento Arcadio Sánchez lo describió como un «hombre muy culto, astuto y de perverso instinto criminal.» El alcalde Nicolás Andreu, por su parte, concluía de forma casi lapidaria, que tratándose de «persona astuta y de fácil palabra, es muy peligroso para nuestra Santa causa.»

Son informes que denotan el profundo odio y rencor del que fue víctima Luis Arráez y que, desde el abuso de poder institucional, descargaron contra la indefensión de un hombre que les había protegido durante la guerra civil y que había abogado, en sus escritos en la prensa, por la bondad como principal y más eficaz postulado del socialismo. ${ }^{74}$ Aunque nada podía importar al auditor un testimonio así, es significativo que ante la gravedad de su situación, se preocupara de mencionar en su pliego de descargos que Josefina Gálvez se despidió de él tras ponerla a salvo en Valencia, «poniendo su ósculo en mi frente y me dijo: es usted un hombre bueno.» Puede que la bondad no sea un tema a tratar por la historiografía, pues como nos recordara Vasili Grossman, discurre por las acciones aisladas de individuos que se comportan como deben en los momentos en los que pueden decidir sobe la vida, la integridad o el bienestar de otros. Pero que lo incluyera en su pliego de descargos nos ayuda a comprender qué tipo de persona era realmente Luis Arráez.

No acabó con su muerte, sin embargo, la persecución del apellido Arráez, pues el 7 de abril de 1941 el Tribunal Regional de Responsabili-

de los medios de represión y control social del Estado por algunos colaboradores que no dudaron en utilizar la nueva situación para acabar con sus vecinos, resolviendo así, mediante la denuncia, disputas que tenían un origen meramente privado. Jan T. Gross, «A Note of Nature of Soviet Totaliarianism», Soviet Studies, Vol. XXXIV, n. ${ }^{\circ}$ 3, july 1982, pp. 367-376. Por su parte, en su teoría de la violencia selectiva aplicada al estudio de la guerra civil en Grecia, Stathis N. Kalivas explica con meridiana claridad el nexo que conecta la intimidad de la violencia y la dimensión local de la guerra civil: «la violencia selectiva requiere información local que, una y otra vez, tiende a proceder de denuncias motivadas por conflictos personales.» Stathis N. Kalivas, op. cit., pp. 249-296, p. 496.

74 Semanario Idella, 23 de abril de 1927. 
dades Políticas de Valencia lo condenaba al pago de 25.000 ptas., sanción que, por el artículo 15 de dicha Ley, heredaban su esposa e hijos. ${ }^{75}$

En cuanto a El Faro, finalmente fue subastada con todo su stock de calzado, pieles y maquinaria, el 3 de mayo de $1940 .{ }^{76}$ Además, los más de treinta mil metros cuadrados de terreno que la cooperativa había adquirido para la construcción de viviendas para los obreros por un valor de 20.850 pesetas en 1936, fueron adquiridos por la firma otrora competidora de Luis Arráez, y cuyos propietarios eran hombres afectos al nuevo régimen, «Agatángelo y Cantó S.A.» Lo hizo por un valor de 19.000 pesetas el 12 de junio de 1943. Un año después, el 24 de agosto, dicha firma donaba parte de los terrenos al Ayuntamiento, representado en dicho acto por su alcalde Nicolás Andreu. Posteriormente, parte de los mismos serían cedidos por éste a la Delegación Nacional del Frente de Juventudes para la instalación de un campo de deportes. ${ }^{77}$

75 AMM-Responsabilidades Políticas.

76 Sentencia del Juzgado de Primera Instancia e Instrucción de Monóvar. Archivo familia Arráez García.

77 Puede verse la evolución de los terrenos en el Registro de la Propiedad de Monóvar. Fincas de Petrer números 5.674, 1.586 y 5.675. Francisco Agatángelo fue uno de los empresarios que declararon contra Luis Arráez, responsabilizándolo de la suerte que corrieron los juzgados por el Tribunal Popular, además de señalarlo como inductor de asesinatos. AHGD, 15797/13, causa 6012. 